\title{
Modeling of the sowing process of row crops in laboratory conditions
}

\author{
Evgeny Zykin ${ }^{1, *}$, Vladimir Kurdyumov ${ }^{1}$, Sergey Albutov ${ }^{1}$, and Oleg Dmitriev ${ }^{1}$ \\ ${ }^{1}$ Department of Agrotechnologies, Machines and Life Safety, Ulyanovsk State Agrarian University, \\ Ulyanovsk, Russia
}

\begin{abstract}
The paper discusses the process of sowing row crops (the formation of a ridge above the seeds and rolling ridges) in laboratory conditions. Taking account of the agrotechnical requirements and physical and mechanical properties of the soil, the reference profile of the soil ridge as well as the original optimization criterion have been adopted. This ridge is formed during sowing, which conditionally can be recognized as ideal. After studying the process of sowing in the tillage bin and statistical processing of the obtained data, the corresponding equations were deduced in which the independent process factors were expressed in natural and in encoded values.
\end{abstract}

\section{Introduction}

There are many crop cultivation technologies in the contemporary world which are intended to increase not only the soil fertility, but also the yield of plants grown $[1,2,3,4$, $5,6,7,8,9]$.

The state of this issue and its analysis showed that the technologies known in science for pre-sowing preparation of the field and the ridge method for sowing row crops are implemented by various tillage and sowing machines, namely, special seeders on the frame of which working bodies are mounted in the form of flat rotating discs. However, to date, there is no theoretical and practical solution aimed at forming a soil ridge above seeds sown into the soil with the use of flat discs. Thus, it is required to substantiate the optimal design and operational parameters of the working bodies of a ridger-seeder.

\section{Objects and research methods}

The authors of the paper developed an innovative ridger-seeder, which simultaneously implements technological operations: cutting weeds, loosening the top soil layer, sowing, forming ridges of the required soil size and density [1, 2, 3].

The seeder includes eight sowing gangs. On each of the gang (Fig. 1) a coulter, two working bodies with flat discs and a ridge-forming roller are mounted.

\footnotetext{
* Corresponding author: evg-zykin@yandex.ru
} 


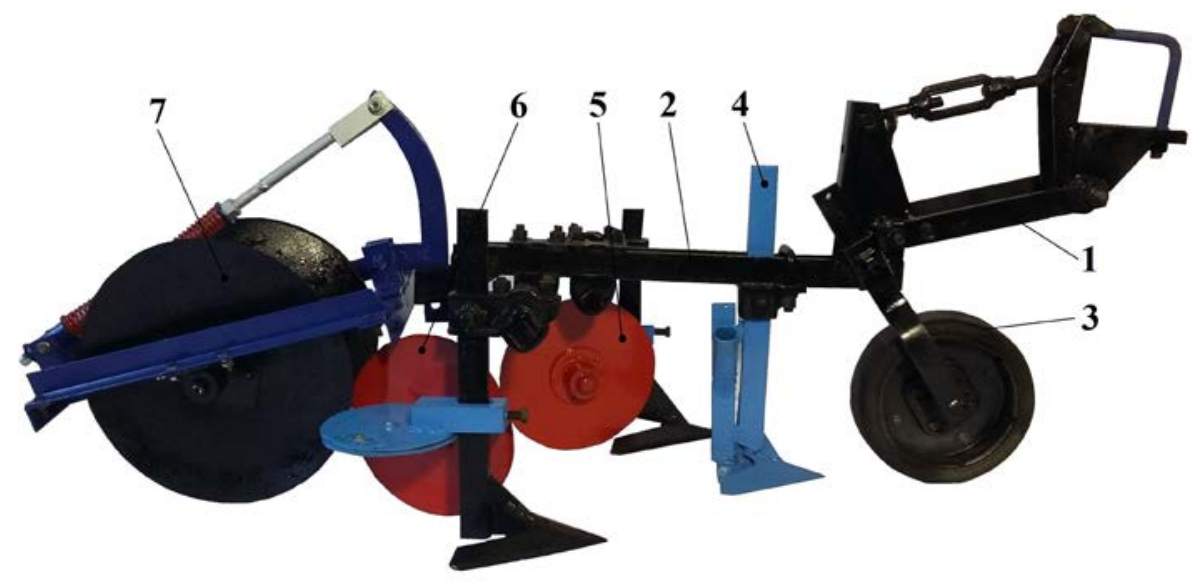

Fig. 1. Ridger-seeder gang: 1 - parallelogram mechanism; 2 - beam; 3 - support wheel; 4 - coulter; 5, 6 - ridge formers; 7 - roller

When the seeder is pulled across the field, the coulter loosens the soil to a depth of 3 $\mathrm{cm}$, forming a bed, and puts seeds on this bed. The moving ridge formers shift the soil from the row-spacing to the sown seeds and form a soil ridge above them. Further, the roller compacts the ridge of soil from three sides and finally forms the soil ridge.

To model the process of sowing row crops in laboratory conditions, we used a complex (Fig. 2), which comprises a tillage bin, a drive unit, a trolley, and measuring instruments.
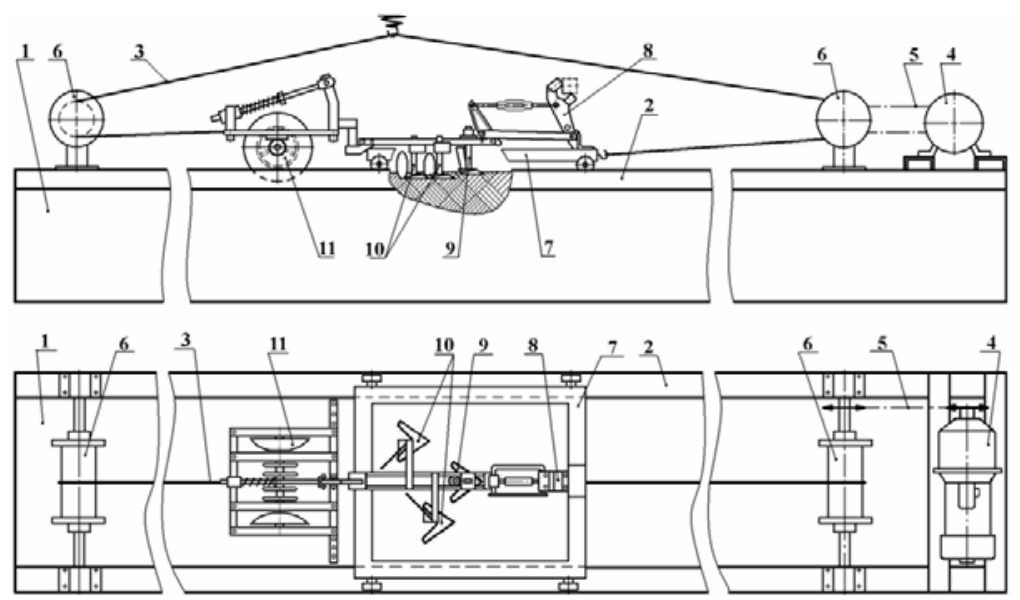

Fig. 2. Complex for modeling the sowing process in laboratory conditions 1 - tillage bin; 2 - rails; 3 cable; 4 - electric motor; 5 - chain transmission; 6 - drums; 7 - trolley; 8 - sowing gang; 9 - coulter; 10 - ridge formers with right and left flat discs; 11 - roller

In order to comply with all agrotechnical indicators, the sowing process modeling in laboratory conditions was carried out in full accordance with the requirements of GOST (state standard) [10].

Taking account of the agrotechnical requirements and physical and mechanical parameters of the soil, the authors adopted the reference profile of the soil ridge, which is formed in the sowing process. This profile is conditionally recognized to be ideal.

Changing various combinations of design and operational parameters of ridge formers in a seeder, the cross-sectional profile of the formed ridges of the soil, as a rule, takes the 
form (Fig. 3).

After modeling the sowing process with various design-mode parameters, we obtained ridge profiles that were compared with the reference soil profile.

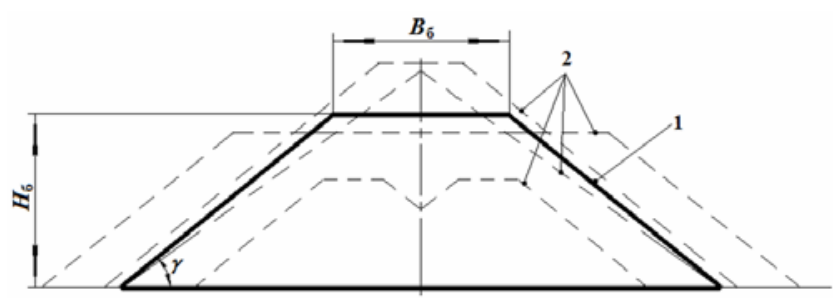

Fig. 3. Profiles of soil ridges formed by ridge formers with flat discs: 1 - reference profile; 2 possible profiles; $B_{\sigma}$ - the width of the upper base of the soil ridge; $H_{\sigma}$ - the height of the soil ridge; $\gamma$ - the natural slope angle of the soil

Qualitative indicators of the formed soil ridge can be assessed by the original optimization criterion $k_{\mathrm{c}}$, which is calculated by the formula:

$$
k_{\text {сэ }}=1-\left|\frac{S_{\text {эт }}-S_{\phi}}{S_{\text {эт }}}\right|,
$$

where $S_{\text {эт }}$ - the cross-section area of the reference soil ridge, the dimensions of which are determined by the agrotechnical requirements for sowing, $\mathrm{m}^{2} ; S_{\phi}$ - the cross-section area of a soil ridge formed by working bodies with flat discs after a seeder pass, $\mathrm{m}^{2}$.

The soil density in the central part of the ridge $\rho, \mathrm{kg} / \mathrm{m}^{3}$ above sown seeds was taken as an optimization criterion during the rolling process.

\section{Research results}

To form the soil ridge when modeling the sowing process flat discs were used with a diameter: $d=0,2 \mathrm{~m}, d=0,25 \mathrm{~m} ; d=0,3 \mathrm{~m}$ and $d=0,35 \mathrm{~m}$ (equations 2, 3, 4 and 5 respectively). The regression equations obtained have the following form:

$$
\begin{aligned}
& k_{\mathrm{cэ}}=0,0994+0,1358 v_{\Gamma}+0,0527 \alpha_{\Gamma}-0,0558 v_{\Gamma}^{2}-0,0002 v_{\Gamma} \alpha_{\Gamma}-0,0011 \alpha_{\Gamma}^{2}, \\
& k_{\mathrm{c} э}=-0,655+1,2591 v_{\Gamma}+0,0568 \alpha_{\Gamma}-0,2724 v_{\Gamma}^{2}-0,021 v_{\Gamma} \alpha_{\Gamma}-0,0006 \alpha_{\Gamma}^{2}, \\
& k_{\mathrm{c} э}=-0,7615+1,4606 v_{\Gamma}+0,041 \alpha_{\Gamma}-0,34 v_{\Gamma}^{2}-0,0146 v_{\Gamma} \alpha_{\Gamma}-0,0005 \alpha_{\Gamma}^{2}, \\
& k_{\mathrm{c} э}=0,1922+0,5632 v_{\Gamma}+0,0212 \alpha_{\Gamma}-0,1635 v_{\Gamma}^{2}+0,0005 v_{\Gamma} \alpha_{\Gamma}-0,0005 \alpha_{\Gamma}^{2} .
\end{aligned}
$$

where $v_{\Gamma}$ - the speed of the ridge formers, $\mathrm{m} / \mathrm{s} ; \alpha_{\mathrm{r}}$ - the angle of attack of a flat disc of each ridge former, in degrees.

With a change in the speed $v_{\mathrm{r}}$ of the ridge formers in the range of $1.2 \ldots 1.6 \mathrm{~m} / \mathrm{s}$, for a fixed angle of attack of flat discs, an increase in the distance of throwing off the soil and, correspondingly, in the geometric dimensions of the formed soil ridge was observed, i.e. $k_{\mathrm{c}}$ $\rightarrow \max$. With an increase in the travel speed of ridge formers from 2.0 to $2.4 \mathrm{~m} / \mathrm{s}$, the soil was thrown by the flat discs of the ridge formers over the formed ridge, and the geometric dimensions of the ridge began to decrease $\left(k_{\mathrm{c} э} \rightarrow \min \right)$.

An increase in the angle $\alpha_{\mathrm{r}}$ of attack of flat discs within $5^{\circ} \ldots 25^{\circ}$, at a constant speed 
$v_{\Gamma}$ of the sowing gang with ridge formers, made it possible to increase the geometric dimensions of the soil ridge and, accordingly, $k_{\mathrm{c} \text {. }}$. With a further increase in the angles of attack of flat discs, a soil ridge is formed with excessively large geometric dimensions, which does not meet our requirements.

Analyzing the equations ( 2 - 5), we can establish that the coefficient $k_{\text {сэ мах }}=0,92$ will have a maximum value when a flat disc with a diameter of $0.35 \mathrm{~m}$ is used on ridge formers.

For a finishing operation - rolling down a soil ridge, a roller was used. To identify the optimal design parameters of the roller and its operating modes, the angles of attack of the spherical discs were varied within $0,5,10,15$, and 20 degrees and compression force of the roller spring (equations $6,7,8,9$, and 10 , respectively):

$$
\begin{aligned}
& \rho=715,9256+470,8169 v+0,4297 F_{\text {пр }}- \\
& -147,3784 v^{2}-0,1337 v F_{\text {пр }}-0,0011 F_{\text {пр }}^{2}, \\
& \rho=850,2969+364,4582 v+0,414 F_{\text {пр }}- \\
& -113,6313 v^{2}-0,1516 v F_{\text {пр }}-0,0008 F_{\text {пр }}^{2}, \\
& \rho=984,6613+258,109 v+0,3982 F_{\text {пр }}- \\
& -79,8874 v^{2}-0,1696 v F_{\text {пр }}-0,0004 F_{\text {пр }}^{2}, \\
& \rho=1037,7573+268,8879 v+0,3203 F_{\text {пр }}- \\
& -84,0579 v^{2}-0,1146 v F_{\text {пр }}-0,0004 F_{\text {пр }}^{2}, \\
& \rho=1104,803+261,3932 v+0,2345 F_{\text {пр }}- \\
& -82,5188 v^{2}-0,0596 v F_{\text {пр }}-0,0004 F_{\text {пр }}^{2},
\end{aligned}
$$

where $\rho$ is the soil density in the central part of the ridge, $\mathrm{kg} / \mathrm{m}^{3} ; v$ is the speed of the roller, $\mathrm{m} / \mathrm{s}$; $F_{\text {пр }}$ - compression force of the roller spring, $\mathrm{N}$.

Having analyzed the equations (6 ... 10), we can conclude that of the nonlinear terms of the equations, the speed of the roller has a strong influence on the optimization parameter. At an angle $\alpha_{\text {сд }}=0^{\circ}$ of attack of each spherical disc, the linear terms of the equation on the soil density in the ridge have an approximately equal effect. With an increase in the angles $\alpha_{\text {сд }}$ from $5^{\circ}$ to $10^{\circ}$, the combination of speed and compression force of the roller spring has the greatest influence on the density of the soil in the ridge, and the compression force of the spring has the least influence. A further increase in the angles of attack of spherical discs within the range of $15^{\circ} \ldots 20^{\circ}$ made it possible to reveal that, the speed of the roller has the greatest influence on the density of the soil, and the compression force of its spring has the least one.

\section{Conclusion}

An analysis of the regression equations (2--5) showed that the main parameters of the equations, on which the quality of the formation of the soil ridge by ridge formers with flat discs most depends on, is their speed of movement, as well as the size of the flat discs and their angles of attack.

By analyzing the process of rolling the ridges of the soil (equations 6 - 10), we can reliably state that the optimum soil density $\rho_{\max }=1205.6 \mathrm{~kg} / \mathrm{m}^{3}$ in the central part of the ridge above the sown seeds can be achieved by using a roller with spherical discs with 
angles of attack $\alpha_{\text {сд }}=10^{\circ}$, and the spring is compressed with a force of $200 \mathrm{~N}$. In addition, the speed of the sowing gang of a ridger-seeder should be within $v=6 \ldots 8 \mathrm{~km} / \mathrm{h}$.

\section{References}

1. Kurdyumov, V.I. A substantiation of the distance between the flat discs of a row cultivator / V.I. Kurdyumov, E.S. Zykin, S.A. Lazutkina // Bulletin of the Ulyanovsk State Agricultural Academy. - 2016. - No. 3 (35). - pp. 174-178.

2. Kurdyumov, V.I. Energy-saving mechanization means of ridge cultivation for row crops / V.I. Kurdyumov, E.S. Zykin // Bulletin of the Ulyanovsk State Agricultural Academy. - 2013. - No. 1 (21). - pp.144-149.

3. Kurdyumov, V.I. The study of the working bodies of the ridge seeder in laboratory conditions / V.I. Kurdyumov, E.S. Zykin, G.L. Tatarov // Bulletin of the Ulyanovsk State Agricultural Academy. - 2015. - No. 3 (31). - pp.121-124.

4. Milyutkin, V. A. Soil-protective agricultural technologies and equipment for cultivating crops / V. A. Milyutkin, N. V. Dolgorukov // Bulletin of the Samara State Agricultural Academy. - 2014. - No. 3. - pp. 37-44.

5. Chatkin, Mikhail Nikolaevich. Improving the functioning of combined tillage machines with active rotary working bodies. 05.20.01 - Technologies and means of mechanization of agriculture; dis. ... the doctors. tech. sciences / M.N. Chatkin. - Saransk, 2007. - p. 450.

6. Block-modular unit for cultivating row crops / A. V. Balashov, A. N. Omarov, J. Zh. Zainushev, A. I. Zavrazhnov, S. V. Soloviev // Bulletin of Michurinsk State Agrarian University. - 2015. - No. 2. - pp. 163-170.

7. Sydyk, D. A. Recommendation on resource-saving technology for the cultivation of grain crops in the conditions of dry farming in southern Kazakhstan / D. A. Sydyk, A. D. Karabalaev, M. A. Sydykov. - Shymkent: Ministry of Agriculture of the Republic of Kazakhstan, 2014. - p. 19. (ISBN 9965-32-4922-2)

8. Akramkhanov, A. Technology of planting crops along the ridges / A. Akramkhanov // Technologies and best practices factsheet. - URL: http://www.cacilm.org/articles/detail/493.

9. Zazulya, A. N. The solution to design problems for creating sowing complexes with the use of applied software / A. N. Zazulya, K. V. Nemtinov // Science in Central Russia. 2016. - No. 1 (19). - pp. 5-14.

10. GOST R 54784-2011. Tests of agricultural machinery. Methods for evaluating technical parameters. Introduced 2012-03-01. - Moscow: Publishing house of standards, 2012. p.23 (Approved and enforced by Order of the Federal Agency for Technical Regulation and Metrology of December 13, 2011 No. 996-st, Moscow). 